\title{
A Signaling Theory of Grade Inflation
}

\author{
William CHAN \\ The University of Hong Kong \\ Li, HaO \\ University of Toronto \\ WING SUEN \\ Chinese University of Hong Kong
}

June 17, 2005

\begin{abstract}
When employers cannot tell whether a school truly has many good students or just gives easy grades, schools have an incentive to inflate grades to help mediocre students, despite concerns about preserving the value of good grades for good students. We construct a signaling model where grades are inflated in equilibrium. The inability to commit to an honest grading policy reduces the informativeness of grades and hurts schools. Grade inflation by one school makes it easier for another school to pass some of its own mediocre students as good ones with inflated grades. Easy grades are strategic complements, providing a channel to make grade exaggeration contagious.
\end{abstract}

Acknowledgments: We thank Bill Dougan, Rick Hanushek, Eddie Lazear, Steven Levitt, Mike Maloney, Curtis Simon, Robert Tamura, and seminar audiences at Stanford University, Clemson University, and the University of Hong Kong for helpful comments. Chan and $\mathrm{Li}$ are grateful for the hospitality of the Hoover Institution. An earlier version of this paper was circulated with the title "Grade Inflation." 


\section{INTRODUCTION}

A common complaint today in higher education is that grades are too high and do not accurately reflect academic performance of college students (Juola [1968]; Carney et al. [1978]; McKenzie [1979]; Kolevzon [1981]; Millman et al. [1983]; Sabot and Wakeman-Linn [1991]; Kuh and $\mathrm{Hu}$ [1999]). It is not unusual to find As being awarded to half or more of a class, with grades below $B$ verging on extinction. High grades can be observed in both public and private institutions, but elite schools have often been singled out as the prime perpetrators of such misleading grading policies (The New York Times, May 22, 1988; Lambert [1993]; Chronicle of Higher Education, November 16, 1994; The Boston Globe, October 7-8, 2001; The Daily Telegraph, August 22, 2004).

Whether grades are too high or not must be understood with reference to certain standards, and the controversy regarding high grades has sometimes been explained as a case of mistaken benchmarks. For example, it has been suggested that college students deserve better grades today because they are better than previous cohorts. According to this argument, academic standards of students have improved over time, and grades must adjust in the same direction to retain their informational content in any absolute sense. This is, however, contradicted by college entrance test scores, which tend to show a declining rather than increasing trend (Wilson [1999]). Another theory, particularly favored by elite schools, is that the grading policy of a school should reflect the quality of its students (Perrin [1998]). Since elite schools have more selective admission standards, higher grades in elite schools are fair and accurate to the extent that they reflect the superior aptitudes of their students relative to those in an average university. However, this argument implicitly assumes that end-users of grades such as potential employers suffer from "grade illusion," and are incapable of taking the difference in student standards into consideration when interpreting grades from different schools. Such illusion on its own does not offer a convincing basis to explain the observed behavior regarding inflated grades, as it is unlikely to affect the entire labor market persistently. It is also inconsistent with the fact that, within a university, the most technically demanding courses and programs into which the brightest students self-select are usually those with the toughest grading policies (Sabot and Wakeman-Linn [1991]; Wilson [1999]). 
An interesting perspective on the issue of the informative content of grades appears in a recent working paper by Ostrovsky and Schwarz [2003]. They argue that if the assignment function from student ability to job desirability is concave, then a school will find it profitable to mix the high-ability students with the low-ability students, through coarsening the information content of grades. To our knowledge, their paper is the only formal model in which users of grades do not suffer from grade illusion. However, their model explains compressed grades more than it does inflated grades. Although grade inflation implies some degree of grade compression (grades cannot be raised beyond $A+$, and the grade distribution becomes concentrated at the upper tail as more and more students get high grades), the reverse is not true. There is no reason that the coarsening of information should take the specific form of inflated grades as opposed to, say, deflated grades.

In this paper we present an equilibrium theory of inflated grades. ${ }^{1}$ The model has two main ingredients. First, schools observe the abilities of their individual students. Second, employers know the distribution of grades in a school, but not the distribution of student abilities within the school. When a school gives a lot of good grades, the labor market cannot fully distinguish whether this is due to an overly liberal grading standard or whether the school is blessed with a large proportion of high-ability students. This gives rise to an incentive for the school to help some of its low-ability students by giving them good grades. However, since employers have rational expectations, this strategy hurts the high-ability students as the value of good grades becomes diluted. A priori, it is not obvious that the terms of such a tradeoff necessarily imply inflated grades. Nevertheless we identify a condition about the objective of the school which ensures that it will inflate grades with a positive probability in equilibrium. We assume that the school cares more about its high-ability students than its low-ability students. This assumption serves to provide the "single-crossing condition" in our signaling model. It implies that schools with more high-ability students have stronger incentives to give more good grades. Therefore in

\footnotetext{
1 Our equilibrium theory is not inconsistent with the idea that grade illusion sometimes occurs. Our basic model shows that grades can be inflated in equilibrium even without grade illusion. A straightforward extension in Section III establishes that the possibility of grade illusion increases the equilibrium incidence of inflated grades.
} 
equilibrium the labor market sees a large percentage of good grades as a signal for a large percentage of high-ability students. This inference property is understood by schools, with the implication that elite schools tend to be more frequent perpetrators of grade exaggeration.

In the "competitive" version of our model, we consider strategic interactions among schools in grading policies that are generated through signaling. To focus on the signaling aspect of the problem, we assume the labor market is sufficiently thick so that schools do not directly compete with one another in placing students in a limited number of job slots. Since wage offers can be conditioned on the individual school of the job applicant and on the grading outcome of the school, any school that wants to maintain the credibility of its grading policy can do so without worrying about inflated grades in other schools. But if the overall quality of student bodies are correlated (either positively or negatively) across different schools, employers can make inferences about student quality in one school by looking at the general distribution of grades in other schools. We show that easy grades are "strategic complements" in such a setting, and this creates a channel that makes grade inflation contagious.

It should be pointed out that the issue addressed in this paper departs from the focus of much of the current debate on grade inflation in academia, which is on the incremental increase of grades over time. The "inflation" analyzed in this paper refers to exaggerated representation of underlying fundamentals, rather than to the time trend. While it is interesting to understand why grades have been creeping up for the last few decades, we feel that it is equally important to explore whether and why grades are too high relative to some well-defined welfare criterion. In our model, grades are too high because they are inflated to signal a high percentage of high-ability students, and schools would be unambiguously better off if they could commit to honestly revealing the true distribution of student quality. Our comparative statics results help one understand what determines the extent of grade inflation. As briefly discussed in the concluding section, our equilibrium model of inflated grades may also provide a foundation for dynamic analysis.

Central to our model is the information asymmetry between providers and end-users of evaluations, and the fact that evaluators care about interests of the evaluated. This 
being the case, it should be clear that our analysis is of more than "academic" interest. Consumers often find themselves in the situation of relying on the product evaluations of more informed experts. Yet, many experts have close ties with producers, so that they may want to misrepresent the information to steer consumers' decisions in their desired directions. Consumers are then left with the task of deciphering the informational content of their recommendations, knowing full well the inherent bias, in much the same way that employers have to interpret the grades of job applicants issued by universities. For example, consumers who consult audio magazines for recommendations on stereo equipment purchases will likely come away with the impression that there is hardly any piece of equipment which the reviewers do not like, simply because advertisement revenue depends on the good relationship with dealers and manufacturers of the very equipment that these magazines review. In this case, indiscriminate raving is constrained only by the need to differentiate the truly outstanding products from the run-of-the-mill types. ${ }^{2}$ Other examples of inflatable ratings that are of great relevance to the business world are company audits prepared by accounting firms and stock market recommendations issued by investment banks. Chinese walls notwithstanding, it is not unreasonable to suspect that auditors and investment analysts may have the interest of their clients rather than that of investors at heart. One manifestation of this incentive structure is the excess of "buy" over "sell" recommendations. ${ }^{3}$ Similarly, an auditor may have the incentive to declare a risky company healthy, if only to maintain a cozy long term relationship with its client. But doing so dilutes the value of the auditor's seal of approval and therefore is not in the interest of its other clients that are financially more sound. The inefficiency of such a game is obvious, and so are the potential dangers. But until a better system is established that provides a greater incentive for truthful transmission of information, analysts and investors alike will continue to play this high stake game of rational deception.

\footnotetext{
2 Our model also contributes to the economic analysis of media bias (e.g., Dyck and Zingales [2002]; Mullainathan and Shleifer [2002]). Just as a school has to play the dual role of the advocate and the judge, the media faces a similar incentive structure.

3 Morgan and Stocken (2003) use a standard cheap talk model to study the incentive structure in stock recommendations. Equilibrium in their model involves information coarsening, but does not entail the feature of exaggeration as in our signaling setup.
} 


\section{A Signaling Model}

A school has two types of students: good students (type $G$ ), with productivity $\omega_{G}$; and mediocre students (type $M$ ), with a lower productivity $\omega_{M}$. There are two possible states of the world. In state $F$, which happens with probability $\pi$, the overall quality of the student body is favorable, with a proportion $\phi_{F}$ of good students. In the unfavorable state $U$, the school has a smaller proportion $\phi_{U}$ of good students. We note that the "school" in our model may be interpreted as a single class, a department, or the whole university. The degree of uncertainty regarding the state may differ, but the anlysis for grade inflation is identical regardless of the level of aggregation.

We assume that individual student types and the state of the world are private knowledge of the school. In particular, potential employers in the labor market observe neither student types nor the state of the world. The state of the world in our model incorporates the result of the school's admission exercise, the success of which in attracting good students can vary in degree from year to year, and also reflects the inherent uncertainty in the outcome of the school's educational process. Even with the same admission policy, and even if the school were able to admit students with the same distribution of observable characteristics over time, the value added of education to individual graduates is stochastic and only imperfectly observed. Given the considerable time that students spend at school and the extensive evaluation by teachers, the school is in a better position to assess the abilities of its graduates than anyone else. For simplicity, we have assumed that the school perfectly observes the type of each individual student and therefore knows the state of the world, but our results hold as long as the potential employers have less knowledge regarding student types and the state of the world. ${ }^{4}$

The school gives each student either grade $A$ or $B$. We assume that the school can send one of two signals: give $A$ to a fraction $\phi_{F}$ of students (easy grading, or $e$ ), or give

\footnotetext{
4 One may argue that employers generally have a reasonable idea of the quality of students in a particular school, from the school's reputation and published admission standards. Yet, in reality, much of the information about individual students or average student quality is supplied by the school, whether in the form of transcripts or reference letters. The reason is that the process by which education enhances the productivity of different students is not well-understood. Students with similar observable characteristics and performance at admission may diverge significantly in their academic achievements and marketability upon graduation.
} 
$A$ to a fraction $\phi_{U}$ of students (tough grading, or $t$ ). Since there may indeed be a large fraction of type $G$ students who deserve an $A$, easy grades are not synonymous to inflated grades. Grades are said to be inflated when easy grading $(e)$ is chosen in the unfavorable state $(U)$.

The assumption of binary signals rules out grading policies that result in a fraction of $A$ grades different from $\phi_{F}$ or $\phi_{U}$, or policies that use more than the two grades $A$ and $B$. It helps us to focus on the issue of inflated grades. ${ }^{5}$ We impose further restrictions on the school's grading policy. When grades are inflated, all the $\phi_{U}$ good students and a measure $\phi_{F}-\phi_{U}$ of mediocre students are chosen randomly to receive grade $A$. Similarly, tough grading in the favorable state means that all mediocre students are $B$-students, but a randomly selected proportion of good students are also given $B$ 's. ${ }^{6}$

The labor market is competitive in that students are paid their expected productivity. Potential employers in the labor market, unable to observe individual student types or the state of the world, can condition the wage offer to a student on his grade $(A$ or $B)$ and on his school's grading outcome $(e$ or $t)$. In other words, when presented with a transcript, an employer would have to make inferences on the student's ability based on expectations about the grade distribution: an $A$ grade by itself is largely meaningless if it is not interpreted in the context of how many $A^{\prime}$ 's are given. ${ }^{7}$ We stress that we are making two assumptions about the labor market here. First, potential employers do not have grade illusion; they hold rational expectations about the relation between the signal and the state. Second, potential employers perfectly observe the grading outcome of the school. These two assumptions are made to focus on the implications of rational expectations. In

\footnotetext{
5 In principle, the cheap talk model of Crawford and Sobel (1982) can be used to construct a model of grade compression, with continuous types and continuous signals. Our model of binary types and binary signals is the simplest kind that avoids the compression issue.

6 Our model of inflated grades is not a standard signaling model, because there are two kinds of signals, individual grades and grades distributions. The assumption of binary signals and the restrictions on the grading policies ensure that our model can be analyzed using the standard techniques in the signaling literature. Note that an implication is that individual grades are never entirely random, and as a result the two signals $e$ and $t$ are not cheap talk.

7 The analogy from price inflation is that nominal prices must be interpreted in the context of the general price level or the money supply.
} 
reality, grade illusion may occur and employers' information on the grading outcome may be imperfect. Later in Section III, we extend the basic model to allow for these possibilities.

The school maximizes a weighted sum of the wage offers to its type $G$ and type $M$ students. This models the school's desire to use its grading policy to help the graduates to obtain the best placement results at the entry level of the labor market. The kind of objective function assumed here may be justified by anticipated donations from successful alumni down the road, by the school's current need to attract good students, or by simple altruistic motives. Let $R$ be the relative weight on the wage offers to good students. We assume that $R>1$; that is, the school cares more about the placement results of its good students than those of the mediocre students. If $R=1$, then any grading policy would give the same level of payoff to the school since the unweighted sum of wage offers to all students is a constant when employers have rational expectations. If $R<1$, the interest of the school and the interest of employers would be diametrically opposed, and grades would cease to become useful signals of student ability. ${ }^{8}$ The assumption of $R>1$ is based on the observation that alumni contributions to their alma mater are likely to be increasing in their abilities: a Nobel prize for a distinguished alumnus will do much more in boosting the academic reputation of a university than producing a number of mediocre scholars, and the school may reap a financial windfall if a star student ends up as the CEO of a major corporation. It is natural that schools would care more about helping their good students successfully launch their careers.

The assumption that $R>1$ provides the "single-crossing" condition (Spence [1973]) in our signaling model. To see this, let $w(A \mid e)$ and $w(B \mid e)$ be the wages paid to $A$ and $B$ students, respectively, when the market observes easy grades given by a school. Similarly, let $w(A \mid t)$ and $w(B \mid t)$ be the wages paid to $A$ and $B$-students when grading is tough. In the favorable state, the difference in payoffs to the school between easy grading and tough grading is

$$
\begin{aligned}
V(e \mid F)-V(t \mid F)= & {\left[R \phi_{F} w(A \mid e)+\left(1-\phi_{F}\right) w(B \mid e)\right] } \\
& -\left[R \phi_{U} w(A \mid t)+R\left(\phi_{F}-\phi_{U}\right) w(B \mid t)+\left(1-\phi_{F}\right) w(B \mid t)\right] .
\end{aligned}
$$

\footnotetext{
8 The school would like to give mediocre students $A$ grades and give good students $B$ grades. Employers would see through this and assign different meanings to $A$ and $B$ grades.
} 
In the unfavorable state, the difference in payoffs is

$$
\begin{aligned}
V(e \mid U)-V(t \mid U)= & {\left[R \phi_{U} w(A \mid e)+\left(\phi_{F}-\phi_{U}\right) w(A \mid e)+\left(1-\phi_{F}\right) w(B \mid e)\right] } \\
& -\left[R \phi_{U} w(A \mid t)+\left(1-\phi_{U}\right) w(B \mid t)\right]
\end{aligned}
$$

The single-crossing condition requires the school to have stronger incentive to choose easy grading in the favorable state than in the unfavorable state. In other words, we require

$$
[V(e \mid F)-V(t \mid F)]-[V(e \mid U)-V(t \mid U)]=(R-1)\left(\phi_{F}-\phi_{U}\right)(w(A \mid e)-w(B \mid t))>0 .
$$

If, in equilibrium, employers expect that an easy $A$ is better than a tough $B$ (which is indeed the case, as we will demonstrate in the following analysis), then the assumption $R>1$ guarantees that the single-crossing condition (1) is satisfied. Intuitively, the school has a stronger incentive to give more $A$ 's (choose easy grading) in the favorable state because there are more good students who deserve the grade. Because of this incentive structure, employers rationally use easy grading as a positive signal for the favorable state. This in turn allows the school to engage in some degree of equilibrium grade exaggeration (choosing easy grading in the unfavorable state), as in a standard signaling model.

\section{Signaling By A Single School}

This section deals with signaling by a single school. The analysis applies more generally to the case of more than one school, provided that the quality of the student body in each school (i.e., the favorable or unfavorable state) is uncorrelated with one another.

Because of the incentive structure induced by the single-crossing property, we look for an "inflationary semi-pooling equilibrium," in which the school adopts the following policy. In the favorable state $F$, the school chooses $e$ and is "honest" about the quality of its students. It gives all the $\phi_{F}$ good students $A$ grades and all the $1-\phi_{F}$ mediocre students $B$ grades. In the unfavorable state $U$, the school randomizes between $e$ and $t$. With probability $1-p$, the school is "honest" and chooses $t$ : only the $\phi_{U}$ good students receive $A$ grades. With probability $p$, the school inflates grades by choosing $e$. In that case, all $\phi_{U}$ good students get $A$ grades, a measure $\phi_{F}-\phi_{U}$ of mediocre students also get $A$ grades, and the remaining $1-\phi_{F}$ mediocre students receive $B$ grades. 
Given such a policy, tough grading is a sure sign of the unfavorable state. The updated probability of state $F$ is zero. Therefore the wage offer to $A$-students is $w(A \mid t)=\omega_{G}$ and the wage offer to $B$-students is $w(B \mid t)=\omega_{M}$. When the market observes easy grading, on the other hand, this could be due to either grade exaggeration or a large fraction of good students. Using Bayes' rule, the updated probability of state $F$ is

$$
q(F \mid e)=\frac{\pi}{\pi+(1-\pi) p}
$$

Competitive wage offer to $A$-students is

$$
w(A \mid e)=q(F \mid e) \omega_{G}+(1-q(F \mid e))\left(\frac{\phi_{U}}{\phi_{F}} \omega_{G}+\left(1-\frac{\phi_{U}}{\phi_{F}}\right) \omega_{M}\right) .
$$

Define

$$
\underline{\omega}=\frac{\phi_{U}}{\phi_{F}} \omega_{G}+\left(1-\frac{\phi_{U}}{\phi_{F}}\right) \omega_{M}
$$

as the wage for $A$-students when the school is believed to have inflated the grades. Note that $\underline{\omega}$ is the lowest possible wage for $A$-students. We can write equation (3) simply as:

$$
w(A \mid e)=q(F \mid e) \omega_{G}+(1-q(F \mid e)) \underline{\omega} .
$$

The wage offer to $B$-students is $w(B \mid e)=\omega_{M}$.

Proposition 1. There is a unique inflationary semi-pooling equilibrium if and only if

$$
\pi<\gamma \equiv \frac{(R-1) \phi_{U}}{(R-1) \phi_{U}+\phi_{F}}
$$

with an equilibrium probability of inflated grades equal to

$$
p^{*}=\frac{\pi}{1-\pi} \frac{\phi_{F}}{\phi_{U}} \frac{1}{R-1}
$$

Proof of Proposition 1. The necessary and sufficient conditions for a semi-pooling equilibrium are: (i) in state $F$ the school weakly prefers $e$ to $t$ :

$$
R \phi_{F} w(A \mid e)+\left(1-\phi_{F}\right) \omega_{M} \geq R \phi_{U} \omega_{G}+R\left(\phi_{F}-\phi_{U}\right) \omega_{M}+\left(1-\phi_{F}\right) \omega_{M}
$$


and (ii) in state $U$ the school is indifferent between $e$ and $t$ :

$$
R \phi_{U} w(A \mid e)+\left(\phi_{F}-\phi_{U}\right) w(A \mid e)+\left(1-\phi_{F}\right) \omega_{M}=R \phi_{U} \omega_{G}+\left(1-\phi_{U}\right) \omega_{M}
$$

Using equations (2) and (3), we can solve for the school's equilibrium probability $p^{*}$ of inflating the grades from condition (ii). The solution is given by equation (7) as stated in the proposition. Condition (6) in the proposition is equivalent to the requirement that $p^{*}<1$. Finally, since $R>1$ and $w(A \mid e)>w(B \mid t)=\omega_{M}$, the single-crossing condition (1) is satisfied. Therefore, condition (ii) implies condition (i). Q.E.D.

In the subsequent analysis it is often convenient to characterize the equilibrium directly in terms of $q(F \mid e)$. To this end, we rewrite the indifference condition between $e$ and $t$ in state $U$ as

$$
R \phi_{U}\left(\omega_{G}-w(A \mid e)\right)=\left(\phi_{F}-\phi_{U}\right)\left(w(A \mid e)-\omega_{M}\right)
$$

The left-hand-side represents the cost of inflating the grades; the right-hand-side represents the benefit. In equilibrium, the wage $w(A \mid e)$ given by (5) must satisfy condition (8). Using the expression for $\gamma$ defined in the statement of Proposition 1, we can state the equilibrium indifference condition simply as:

$$
q(F \mid e)=\gamma
$$

Intuitively speaking, $q(F \mid e)$ is the probability in state $U$ of "fooling" the market into believing that the state is favorable. An inflationary semi-pooling equilibrium occurs when the school's probability $p$ of inflating the grades is such that its equilibrium probability $q(F \mid e)$ of fooling the market is equal to $\gamma$. Note that $\gamma$ is a number between 0 and 1 . The function $q(F \mid e)$ is decreasing in the probability of inflated grades $p$, with $q(F \mid e)=1$ at $p=0$ and $q(F \mid e)=\pi$ at $p=1$. Therefore, a unique solution $p^{*} \in(0,1)$ exists for any $\gamma \in(\pi, 1)$.

What happens if $\gamma \leq \pi$ ? An "inflationary pooling equilibrium" would result, in which the school chooses easy grading in both state $F$ and state $U$ with probability 1 . 
Proposition 2. There exists an inflationary pooling equilibrium if and only if $\pi \geq \gamma$.

Proof of Proposition 2. We need to prove the school weakly prefers $e$ to $t$ in both state $U$ and state $F$ if $\pi \geq \gamma$. In a pooling equilibrium, since the school always chooses $e$, the market does not update its probability assessment for state $F$ upon observing easy grading. The competitive wage offer to $A$-students is

$$
w(A \mid e)=\pi \omega_{G}+(1-\pi) \underline{\omega} .
$$

The wage offer to $B$-students is $\omega_{M}$. Let the out-of-equilibrium belief be that the state is $U$ when $t$ is observed. Then the competitive wage offer would be $\omega_{G}$ to $A$-students and $\omega_{M}$ to $B$-students. Since $\pi \geq \gamma$, one can verify that the school weakly prefers $e$ to $t$ in state $U$. Since the single-crossing condition is satisfied, weak preference for $e$ in state $U$ implies strict preference for $e$ in state $F$.

Consider the reverse statement. In an inflationary pooling equilibrium, when deviation to $t$ occurs, $A$-students get $\omega_{G}$ while the wage $w(B \mid t)$ for $B$-students depends on the outof-equilibrium belief. However, for any belief, we have $w(B \mid t) \geq \omega_{M}$. In equilibrium the school weakly prefers $e$ to $t$ in state $U$. Therefore,

$$
R \phi_{U} w(A \mid e)+\left(\phi_{F}-\phi_{U}\right) w(A \mid e)+\left(1-\phi_{F}\right) \omega_{M} \geq R \phi_{U} \omega_{G}+\left(1-\phi_{U}\right) w(B \mid t)
$$

where $w(A \mid e)$ is given by equation (10). Since $w(B \mid t) \geq \omega_{M}$, the above inequality implies that $w(A \mid e) \geq q(F \mid e) \omega_{G}+(1-q(F \mid e)) \underline{\omega}$, from which it follows that $\pi \geq \gamma$.

Q.E.D.

Signaling models are often plagued by multiplicity of equilibria. Though the inflationary (semi-pooling or pooling) equilibrium we have identified is natural in our setting, there may be other equilibrium outcomes in our model, for example, grade deflation. If this is the case, the comparative statics and welfare results that we will present below would lose much of their force, because it is not clear which of the multiple equilibria would be observed. In Appendix A we show how existence of other types of equilibria is ruled out by a combination of the single-crossing condition and standard refinement criteria in the signaling literature. 


\section{A. Comparative Statics}

Propositions 1 and 2 imply that the school's equilibrium probability of inflating the grades (choosing $e$ in state $U$ ) is

$$
p^{*}=\min \left\{\frac{\pi}{1-\pi} \frac{\phi_{F}}{\phi_{U}} \frac{1}{R-1}, 1\right\}
$$

Equation (11) shows that a greater concern for the good students lowers the school's probability of inflating the grades. Intuitively, a greater $R$ increases the cost of inflating the grades (the left-hand-side of equation (8)) while keeping the benefit unchanged. As a result equilibrium $p^{*}$ must decrease to increase $q(F \mid e)$ and $w(A \mid e)$ in order to restore the indifference condition (9).

An increase in $\phi_{F} / \phi_{U}$ increases the school's equilibrium probability of inflating the grades. Increases in $\phi_{F} / \phi_{U}$ may occur when employers face a greater uncertainty in the inference of abilities from grades due to a more diverse student body (the variance of the two-point distribution regarding the state is proportional to the squared difference between $\phi_{F}$ and $\phi_{U}$.) In terms of our model, the ratio $\phi_{F} / \phi_{U}$ represents the feasible extent of grade exaggeration: since the fraction of inflated $A$ grades is $1-\phi_{U} / \phi_{F}$, the higher the ratio, the more misleading grades the school reports when grades are inflated. ${ }^{9}$ From condition (8), one can see that an increase in $\phi_{F} / \phi_{U}$ raises the benefit of inflation relative to the cost: in state $F$, the number of mediocre students who benefit from grade exaggeration is $\phi_{F}-\phi_{U}$, and the number of good students who bear the cost of a diminished $A$ grade is $\phi_{U}$. As a result equilibrium $p^{*}$ must decrease to increase $q(F \mid e)$ in order to restore the indifference condition.

One interesting observation is that the probability of inflating the grades does not depend on the productivity premium $\omega_{G} / \omega_{M}$. This is because an increase in productivity premium $\omega_{G} / \omega_{M}$ has two opposing effects. On one hand, from equation (5), raising $\omega_{G} / \omega_{M}$ increases $w(A \mid e)$ for any given equilibrium probability of grade inflation. In the absence

9 In our two-state model with binary student types, changes in $\phi_{F}$ and $\phi_{U}$ affect not only the quality of the student body, but the meaning of the grading outcomes ( $e$ and $t$ ) as well. Given this feature of our model, we prefer to interpret $\phi_{F} / \phi_{U}$ as a parameter that describes the feasible extent of grade inflation as opposed to one that is about average student quality. 
of other effects, this would force $p^{*}$ to go up in order to restore the indifference condition (9). On the other hand, from equation (8) we can see that raising $\omega_{G} / \omega_{M}$ increases the cost of inflating the grades relative to the benefit, which tends to reduce $p^{*}$. These two effects exactly cancel each other given the linear feature of the model.

Equation (11) also shows that the school's probability of inflating the grades increases with the probability of the favorable state. An increase in $\pi$ directly affects the cost and the benefit of inflating the grades only through its effect on $w(A \mid e)$. From equation (2), a greater $\pi$ increases the likelihood that easy grading is justified by the favorable state. This tends to raise $w(A \mid e)$, decreasing the cost and increasing the benefit of inflating the grades. To restore indifference, the school must inflate more often to reduce $w(A \mid e)$ back to its original level.

Most of the reports on inflated grades in the popular press focuses on elite schools, perhaps because these schools are more visible and make better news stories. Whether elite schools in fact are more prone to inflating the grades awaits more rigorous empirical analysis, but our comparative statics exercise makes two cautionary points. First, an elite school may be more likely to attract good students or more likely to produce good students (a greater $\pi$ ), which would result in a greater $p^{*} \cdot{ }^{10}$ An elite university can claim with a straight face that most of its students get $A$ 's because they are all good students - often the claim is indeed true, but a similar claim made by a lesser school is less convincing. Second, elite schools tend to exaggerate grades more because of greater credibility of their inflated claims and therefore higher expected benefit from making such claims, not because their students are "better" per se. As discussed above, proportionate increases in both $\omega_{G}$ and $\omega_{M}$, which imply a higher quality of students in both states, have no effect on the school's equilibrium probability of inflating the grades, even though both the good and the mediocre students in an elite school command higher wages than graduates of other schools. The same is true with proportionate increases in both $\phi_{U}$ and $\phi_{F}$.

Additional comparative statics results can be obtained if we allow for the possibility of grade illusion or imperfect observation of the grading outcome. The structure of the

\footnotetext{
10 Recent accounting scandals took place at a time when investors were exceptionally bullish about the economy. Perhaps inflated profit figures would have been much less credible at leaner times.
} 
two extensions is similar; for convenience we present them simultaneously. Let $\eta \in[0,1)$ be the fraction of potential employers that take grades at face values or the fraction of employers that do not observe the grading outcome of the school. In both cases, the critical equilibrium condition remains equation (9), the indifference condition in state $U$ between $e$ and $t .{ }^{11}$ However, instead of $q(F \mid e)$, we have the average probability of fooling the market, given by $(1-\eta) q(F \mid e)+\eta \hat{q}$, where $q(F \mid e)$ is the same as before, defined by equation $(2)$, and $\hat{q}$ is the effective probability of fooling the market with a grade $A$ when potential employers either take grades at face values or make an uninformed guess at the state without knowing the grading outcome. In the first case, $\hat{q}=1$, because an employer with grade illusion takes the grade $A$ as the definitive sign of a good student. In the second case, $\hat{q}=\pi$, because an employer without the knowledge of the signal retains the prior belief about the state. ${ }^{12}$ Since $q(F \mid e)$ lies between $\pi$ and 1 , an increase in $\eta$ shifts up the average probability of fooling the market in the case of grade illusion, and shifts down the average probability in case of imperfect observation of the signal. Thus, the equilibrium probability of inflating the grades increases with the possibility of grade illusion and decreases with the possibility of imperfect observation.

So far, we have not considered possible detection of "mislabeling" of students by employers, but this can also be easily incorporated. Suppose there is a certain chance that mediocre students with inflated grades will be identified. This would impose a cost on the school, because the wages for such students will be reduced or the reputation of the school will be damaged. In this case, the school's payoff if it chooses easy grading under the unfavorable state is

$$
R \phi_{U} w(A \mid e)+\left(\phi_{F}-\phi_{U}\right)(w(A \mid e)-c)+\left(1-\phi_{F}\right) w(B \mid e)
$$

\footnotetext{
11 It is straightforward to show that the single-crossing condition remains valid in both extensions. Thus, as in the basic model, indifference in state $U$ implies strict preference for $e$ in state $F$.

12 Alternatively, one can imagine that an uninformed employer who gets an $A$-student updates the belief according to the equilibrium strategy and the assumption that the grade is randomly drawn from the entire grade distribution. This yields $\hat{q}=\pi \phi_{F} /\left[\pi \phi_{F}+(1-\pi)\left(p \phi_{F}+(1-p) \phi_{U}\right)\right]$. It is straightforward to show that for any probability $p$ of inflating the grades less than $1, \hat{q}<q(F \mid e)$. Thus, the conclusion remains that an increase in $\eta$ reduces the equilibrium probability of inflating the grades.
} 
where $c$ is the expected unit cost of exaggerating a student's grade. Following the same analysis as before, it can be shown that, in a semi-pooling equilibrium, the school's equilibrium probability of inflating the grades is decreasing in the "dishonesty cost" $c$. It is conceivable that the cost $c$ would differ across academic disciplines. Competence in the physical sciences and engineering is usually more easily established through examinations than is competence in the social sciences and humanities. A physics department that is caught giving a mediocre student an $A$ grade may suffer a great loss in reputation as employers attribute the mislabeling to lax standards. A sociology department caught in the same situation may be given the benefit of the doubt as it is difficult for the department to reliably assess the quality of its students to begin with. Therefore, the dishonesty cost is probably higher in physics than in sociology. This may explain why the problem of inflated grades is often found to be more serious in the social sciences and humanities than in the natural sciences (Sabot and Wakeman-Linn [1991]; Wilson [1999]). ${ }^{13}$

The idea of a dishonesty cost to the school can be profitably applied to shed some light on the question of why the problem of inflated grades has become worse in recent decades. Some authors have suggested that, over the years, there has been an increasing consumerism in higher education, with students and parents expecting higher returns (in job or graduate school placements) to their hefty investments, to be facilitated by lenient grading (Levine and Cureton [1998]). The pressure on instructors has been further aggravated by the increasing use of course evaluation in tenure and promotion decisions. With a higher personal cost of antagonizing students, many instructors simply accede to students' demand and effectively resort to bribing students for higher ratings and enrollments with easy grades (Nichols and Soper [1972], Kelley [1972], Capozza [1973], Nelson and Lynch [1984], Dickson [1984], and Zangenehzadeh [1988]). Occasional admonitions notwithstanding, departments and administrations apparently have done little to reverse the trend, perhaps mindful of the potential implications on resources. It appears, therefore, that the grading policies adopted by instructors are not inconsistent with the objective of the university. In terms of our model, this amounts to an increase over time in the concern

13 Economics is an exception among the social sciences: it is among the group of low-grading departments. 
for the overall placement results of the students, relative to the dishonesty $\operatorname{cost} c$, in the school's objective function. These changes would raise the incentive to exaggerate grades, resulting in the inflationary trend that has been so widely reported.

\section{B. Welfare Analysis}

Grade exaggeration affects the welfare of good and mediocre students differently. In equilibrium a good student always gets grade $A$, and receives an expected payoff of

$$
\pi w(A \mid e)+(1-\pi)\left(p^{*} w(A \mid e)+\left(1-p^{*}\right) \omega_{G}\right)
$$

Since $\omega_{G}>w(A \mid e)$, the good student is worse off when grades are inflated $\left(p^{*}>0\right)$ than he would be if there were no grade inflation. Furthermore, the welfare of the good student falls monotonically with the school's probability of inflating the grades. A higher $p^{*}$ adversely affects a good student in two ways: it reduces the probability $(1-\pi)\left(1-p^{*}\right)$ of receiving the deserved wage $\omega_{G}$ when the school chooses tough grading, and it reduces the market estimate $w(A \mid e)$ of the productivity of $A$-students when the school chooses easy grading.

The opposite is true with a mediocre student. He gets grade $B$ in the favorable state and has a probability $\left(\phi_{F}-\phi_{U}\right) /\left(1-\phi_{U}\right)$ of getting an inflated grade $A$ in the unfavorable state. His expected equilibrium payoff is:

$$
\pi \omega_{M}+(1-\pi)\left(\left(1-p^{*}\right) \omega_{M}+p^{*}\left(\frac{1-\phi_{F}}{1-\phi_{U}} \omega_{M}+\frac{\phi_{F}-\phi_{U}}{1-\phi_{U}} w(A \mid e)\right)\right) .
$$

Since $w(A \mid e)>\omega_{M}$, a mediocre student is better off when grades are inflated than what he would otherwise be if there were no grade inflation. Furthermore his welfare rises monotonically with the school's probability of inflating the grades. An increased use of grade inflation improves his chance of receiving a higher wage $w(A \mid e)$ instead of $\omega_{M}$, but reduces the wage offer $w(A \mid e)$ at the same time. The net effect is positive, as the derivative of the equilibrium payoff with respect to $p$ is:

$$
(1-\pi) \frac{\phi_{F}-\phi_{U}}{1-\phi_{U}}\left(\underline{\omega}-\omega_{M}+q^{2}(F \mid e)\left(\omega_{G}-\underline{\omega}\right)\right)>0 .
$$

Therefore, the two types of students have opposing interests with regard to grade exaggeration. 
Although grade exaggeration hurts good students and benefits mediocre ones, the school is unambiguously worse off in a signaling equilibrium compared to a situation where student ability is public information. Under public information, all good students get $A$ grades and are paid $\omega_{G}$, while all mediocre students get $B$ grades and are paid $\omega_{M}$. The school's payoff is then

$$
\pi\left(R \phi_{F} \omega_{G}+\left(1-\phi_{F}\right) \omega_{M}\right)+(1-\pi)\left(R \phi_{U} \omega_{G}+\left(1-\phi_{U}\right) \omega_{M}\right)
$$

With imperfect information, the school's expected equilibrium payoff in state $F$ is

$$
R \phi_{F} w(A \mid e)+\left(1-\phi_{F}\right) \omega_{M}
$$

and the expected payoff in state $U$ is

$$
\left(1-p^{*}\right)\left(R \phi_{U} \omega_{G}+\left(1-\phi_{U}\right) \omega_{M}\right)+p^{*}\left(R \phi_{U} w(A \mid e)+\left(\phi_{F}-\phi_{U}\right) w(A \mid e)+\left(1-\phi_{F}\right) \omega_{M}\right) .
$$

In a semi-pooling equilibrium, $p^{*}$ is such that the school is indifferent between the two signals $e$ and $t$, so the expected payoff in state $U$ is simply

$$
R \phi_{U} \omega_{G}+\left(1-\phi_{U}\right) \omega_{M}
$$

The school is worse off in the semi-pooling equilibrium compared to the case when student ability is public information, because grade exaggeration lowers the wage offer to its good students in state $F$ from $\omega_{G}$ to $w(A \mid e)$, without increasing the school's expected payoff in state $U$. In a pooling equilibrium with $p^{*}=1$, the expected payoff in state $U$ is

$$
R \phi_{U} w(A \mid e)+\left(\phi_{F}-\phi_{U}\right) w(A \mid e)+\left(1-\phi_{F}\right) \omega_{M}
$$

where $w(A \mid e)$ is given by equation (10). A few steps of straightforward calculations reveal that the school's equilibrium expected payoff is lower than in the case of public information if and only if

$$
(R-1)(1-\pi)\left(1-\phi_{U} / \phi_{F}\right)\left(\pi \phi_{F}+(1-\pi) \phi_{U}\right)\left(\omega_{G}-\omega_{M}\right)>0,
$$

which is true because $R>1$. 
The result that the school is worse off in a signaling equilibrium compared to the case when student ability is public information is due to the inability of the school to commit to an honest grading policy. The private incentives to tinker with grades and help a few mediocre students hurt the school because the market understands such incentives and makes adjustments in wage offers accordingly. This result is similar in spirit to the celebrated result about rules versus discretion in the literature on monetary inflation (Kydland and Prescott [1977]).

In the present model, employers always pay workers their expected productivities. Their welfare is unaffected by grade exaggeration. In a more general setting, however, employers care about optimal task assignment according to ability (e.g., Gibbons and Waldman [1999]) and about optimal sorting by worker ability (e.g., Kremer [1993]). By coarsening the informational content of grades as signals of worker quality, grade exaggeration will have a negative effect on total output in such kind of environments.

\section{Signaling By Two Schools}

Our model of signaling by a single school indicates that the problem of inflated grades is not merely one of "racing to the bottom" in the competition among schools. The phenomenon arises more fundamentally from the inability of schools to commit to an honest grading policy in an environment with private information. Nevertheless introducing strategic interactions among schools in this kind of environment is useful, because it can help us address questions such as the following: Do strategic interactions among schools tend to encourage or constrain grade exaggeration? How does grade exaggeration spread from one school to another?

In principle one can consider many kinds of strategic interactions among schools. For example, schools may compete in helping to place their graduates in a fixed number of desirable job slots, or they may compete in trying to attract the most promising incoming students. To focus on the signaling aspect of school competition, we choose to ignore such direct competitions. Instead our attention is restricted to an environment in which the labor market is sufficiently thick that all students receive wage offers equal to their 
expected marginal product. In this environment the only channel through which schools interact with one another is the signals they send through grades.

Consider a model in which there are two identical schools, 1 and 2. Each school knows its own state but not the state of the other school. Employers do not observe the state in either school. The correlation structure of the states in the two schools is public information. A simple one-parameter model of correlation is given in the following contingency table:

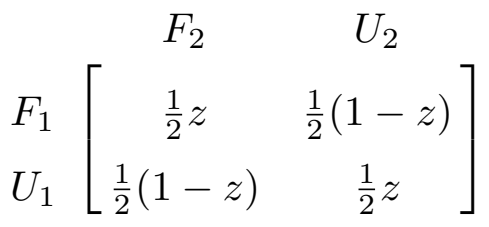

In this model,

$$
z=\operatorname{Pr}\left[F_{j} \mid F_{i}\right]=\operatorname{Pr}\left[U_{j} \mid U_{i}\right]
$$

for $i \neq j(i, j=1,2)$. The parameter $z$ varies between 0 (perfect negative correlation) and 1 (perfect positive correlation). When $z=\frac{1}{2}$, the two schools have independent states. Note also that, for simplicity, we have eliminated the parameter $\pi$ in the single-school model. In the present two-school model, the unconditional probability of the favorable state in either school is:

$$
\operatorname{Pr}\left[F_{1}\right]=\operatorname{Pr}\left[F_{2}\right]=\frac{1}{2}
$$

Once again, we consider an inflationary semi-pooling equilibrium, in which each school $i=1,2$ chooses $e_{i}$ in state $F_{i}$ and randomizes between $e_{i}$ and $t_{i}$ in state $U_{i}$. Let $p_{i}$ be the probability that school $i$ chooses easy grading in the unfavorable state.

In such an equilibrium, the conditional probabilities are given by:

$$
\begin{aligned}
q\left(F_{1} \mid e_{1}, e_{2}\right) & =\frac{\frac{1}{2} z+\frac{1}{2}(1-z) p_{2}}{\frac{1}{2} z+\frac{1}{2}(1-z)\left(p_{1}+p_{2}\right)+\frac{1}{2} z p_{1} p_{2}} ; \\
q\left(F_{1} \mid e_{1}, t_{2}\right) & =\frac{\frac{1}{2}(1-z)}{\frac{1}{2}(1-z)+\frac{1}{2} z p_{1}} \\
q\left(F_{1} \mid t_{1}, e_{2}\right) & =q\left(F_{1} \mid t_{1}, t_{2}\right)=0 .
\end{aligned}
$$

The competitive wage offer to $B$-students is always equal to $\omega_{M}$. The wage offer to $A$ - 
students depends on observed grading outcomes:

$$
\begin{aligned}
& w\left(A_{1} \mid e_{1}, e_{2}\right)=q\left(F_{1} \mid e_{1}, e_{2}\right) \omega_{G}+\left(1-q\left(F_{1} \mid e_{1}, e_{2}\right)\right) \underline{\omega} ; \\
& w\left(A_{1} \mid e_{1}, t_{2}\right)=q\left(F_{1} \mid e_{1}, t_{2}\right) \omega_{G}+\left(1-q\left(F_{1} \mid e_{1}, t_{2}\right)\right) \underline{\omega} ; \\
& w\left(A_{1} \mid t_{1}, e_{2}\right)=w\left(A_{1} \mid t_{1}, t_{2}\right)=\omega_{G}
\end{aligned}
$$

where $\underline{\omega}$ is the wage for an $A$-student when his school is believed to have inflated its grades, as defined by equation (4) in the previous section.

We first establish that the single-crossing condition continues to hold in the two-school case. We will show that for any $z \in(0,1)$, if school 1 , say, weakly prefers easy grading to tough grading in state $U_{1}$, then it strictly prefers easy grading to tough grading in state $F_{1}$. Let $w\left(A_{1} \mid U_{1}\right)$ be school 1's expectation about the wage of its $A$-students when it chooses easy grading in the unfavorable state. We have

$$
w\left(A_{1} \mid U_{1}\right)=(1-z) w\left(A_{1} \mid e_{1}, e_{2}\right)+z\left(p_{2} w\left(A_{1} \mid e_{1}, e_{2}\right)+\left(1-p_{2}\right) w\left(A_{1} \mid e_{1}, t_{2}\right)\right) .
$$

Similarly, let $w\left(A_{1} \mid F_{1}\right)$ be school 1's expectation about the wage of its $A$-students when it chooses easy grading in the favorable state:

$$
w\left(A_{1} \mid F_{1}\right)=z w\left(A_{1} \mid e_{1}, e_{2}\right)+(1-z)\left(p_{2} w\left(A_{1} \mid e_{1}, e_{2}\right)+\left(1-p_{2}\right) w\left(A_{1} \mid e_{1}, t_{2}\right)\right) .
$$

The single-crossing condition requires that $V\left(e_{1} \mid F_{1}\right)-V\left(t_{1} \mid F_{1}\right)>V\left(e_{1} \mid U_{1}\right)-V\left(t_{1} \mid U_{1}\right)$. Following the same manipulations as those in Section III, this can be written as:

$$
(R-1)\left(\phi_{F}-\phi_{U}\right)\left(w\left(A_{1} \mid U_{1}\right)-\omega_{M}\right)+R \phi_{F}\left(w\left(A_{1} \mid F_{1}\right)-w\left(A_{1} \mid U_{1}\right)\right)>0 .
$$

Since $R>1$ and $w\left(A_{1} \mid U_{1}\right)>\omega_{M}$, the first term in the above equation is positive. Furthermore one can verify that, for any $z \in(0,1)$,

$$
w\left(A_{1} \mid F_{1}\right)-w\left(A_{1} \mid U_{1}\right)=\left(1-p_{2}\right)(2 z-1)\left(w\left(A_{1} \mid e_{1}, e_{2}\right)-w\left(A_{1} \mid e_{1}, t_{2}\right)\right) \geq 0 .
$$

Therefore the single-crossing condition is indeed satisfied.

In the single-school case, the assumption that $R>1$ helps to ensure that the incentive for a school to choose easy grading is greater in the favorable state than in the unfavorable 
state. In the present case, there is another reason that the single-crossing condition is satisfied: a school expects its $A$-students to receive higher expected wages in the favorable state than in the unfavorable state, i.e., $w\left(A_{1} \mid F_{1}\right) \geq w\left(A_{1} \mid U_{1}\right)$. This is because with negative correlation, in state $F_{1}$ school 2 is likely to be in state $U_{2}$ and with probability $1-p_{2}$ will not inflate. This helps school 1's $A$-students because when the states are negatively correlated, employers attach a higher probability to $F_{1}$ upon observing $\left(e_{1}, t_{2}\right)$. With positive correlation, the reasoning is the opposite and but reaches the same conclusion. In state $F_{1}$, school 2 is likely to be in state $F_{2}$ and will for sure have easy grades. This again helps school 1's $A$-students. Due to positive correlation of the states, employers attach a higher probability to $F_{1}$ if the signal is $\left(e_{1}, e_{2}\right)$.

Let us consider the symmetric case. Let $p$ be the common probability of easy grading in the unfavorable state. In an inflationary semi-pooling equilibrium, school 1 must be indifferent between easy grading and tough grading in the unfavorable state. Straightforward calculations lead to the following indifference condition:

$$
k(p)=\gamma,
$$

where the parameter $\gamma$ is given by equation (6), and the function $k(p)$ is given by

$$
k(p)=(1-z+z p) q\left(F_{1} \mid e_{1}, e_{2}\right)+z(1-p) q\left(F_{1} \mid e_{1}, t_{2}\right) .
$$

As in the single-school case, the function $k(p)$ can be interpreted as the probability in state $U_{i}$ of "fooling" the market when school $i$ chooses easy grading. Equation (13) above reduces to equation (9) in the single-school case when $z=\frac{1}{2}$ (the prior probability of state $F$ is fixed at $\frac{1}{2}$ in the imperfect correlation model we have constructed.) In state $U_{1}$, school 1 expects that the other school chooses easy grading with probability $1-z+z p$, in which case the market assessment for the probability of state $F_{1}$ is $q\left(F_{1} \mid e_{1}, e_{2}\right)$. If the other school chooses tough grading, on the other hand, the market assessment for the probability of state $F_{1}$ is $q\left(F_{1} \mid e_{1}, t_{2}\right)$. In any inflationary semi-pooling equilibrium, the probability that school 1 in state $U_{1}$ fools the market is equal to $\gamma$.

Proposition 3. For any $z \in(0,1)$, there exists an inflationary semi-pooling equilibrium if $\gamma>\frac{1}{2}$, and there exists an inflationary pooling equilibrium if $\gamma \leq \frac{1}{2}$. Furthermore, if $z \leq \frac{1}{2}$ and $\gamma>\frac{1}{2}$, the inflationary semi-pooling equilibrium is unique. 
Proof of Proposition 3. For any $z \in(0,1)$, the function $k(p)$ is continuous in $p$ with $k(0)=1$ and $k(1)=\frac{1}{2}$. Therefore, if $\gamma>\frac{1}{2}$, there exists a $p^{*} \in(0,1)$ such that $k\left(p^{*}\right)=\gamma$. Since school $i=1,2$ is indifferent between $e_{i}$ and $t_{i}$ in state $U_{i}$, the single-crossing condition implies that it will choose $e_{i}$ in state $F_{i}$. Uniqueness of equilibrium is established by the monotonicity of the $k(p)$ function. One can verify that both $q\left(F_{1} \mid e_{1}, e_{2}\right)$ and $q\left(F_{1} \mid e_{1}, t_{2}\right)$ are decreasing in $p$. Further, $q\left(F_{1} \mid e_{1}, e_{2}\right) \leq q\left(F_{1} \mid e_{1}, t_{2}\right)$ if and only if $z \leq \frac{1}{2}$. Thus, if $z \leq \frac{1}{2}$, then $k^{\prime}(p)<0$ and the solution to the equation $k(p)=\gamma$ is unique.

In an inflationary pooling equilibrium, each school $i=1,2$ chooses $e_{i}$ in both states with probability 1 . Upon observing $e_{1}$ and $e_{2}$, we have $q\left(F_{1} \mid e_{1}, e_{2}\right)=\frac{1}{2}$. Competitive wage offer to $A$-students is

$$
w\left(A_{1} \mid e_{1}, e_{2}\right)=\frac{1}{2} \omega_{G}+\frac{1}{2} \underline{\omega} .
$$

Let the out-of-equilibrium belief be that school 1's state is $U_{1}$ when $t_{1}$ is observed. Then the competitive wage offer is $\omega_{G}$ for $A$-students. One can verify that since $\gamma \leq \frac{1}{2}$, in state $U_{1}$ school 1 weakly prefers $e_{1}$ to $t_{1}$. By the single-crossing condition, weak preference for $e_{1}$ in state $U_{1}$ implies strict preference for $e_{1}$ in state $F_{1}$.

Q.E.D.

Multiple semi-pooling equilibria can occur when $z$ is close to 1 . The logic behind the difference between negative and positive correlation is quite intuitive. In both cases, the condition for an inflationary semi-pooling equilibrium is that the probability $p$ of inflating the grades is such that the probability $k(p)$ of fooling the market is equal to the exogenous parameter $\gamma$. Under negative correlation, $k(p)$ decreases with $p$ both because the market becomes more skeptical of good grades $\left(q\left(F_{1} \mid e_{1}, e_{2}\right)\right.$ and $q\left(F_{1} \mid e_{1}, t_{2}\right)$ decrease $)$ and because it is more likely that the market observes easy grades in both schools, which is bad news because the states are negative correlated $\left(q\left(F_{1} \mid e_{1}, e_{2}\right)<q\left(F_{1} \mid e_{1}, t_{2}\right)\right.$ when $\left.z<\frac{1}{2}\right)$. Monotonicity of $k(p)$ means that there can be at most one semi-pooling equilibrium. The situation is different with positive correlation. A greater $p$ still means a more skeptical market, but having easy grades in both schools is now good for the schools. As a result $k(p)$ can increase over some range of $p$. Indeed, when $z$ is close to 1 , the function $k(p)$ is non-monotone so that multiple semi-pooling equilibria occur for $\gamma$ just below and just above $\frac{1}{2}$. See Figure I. 


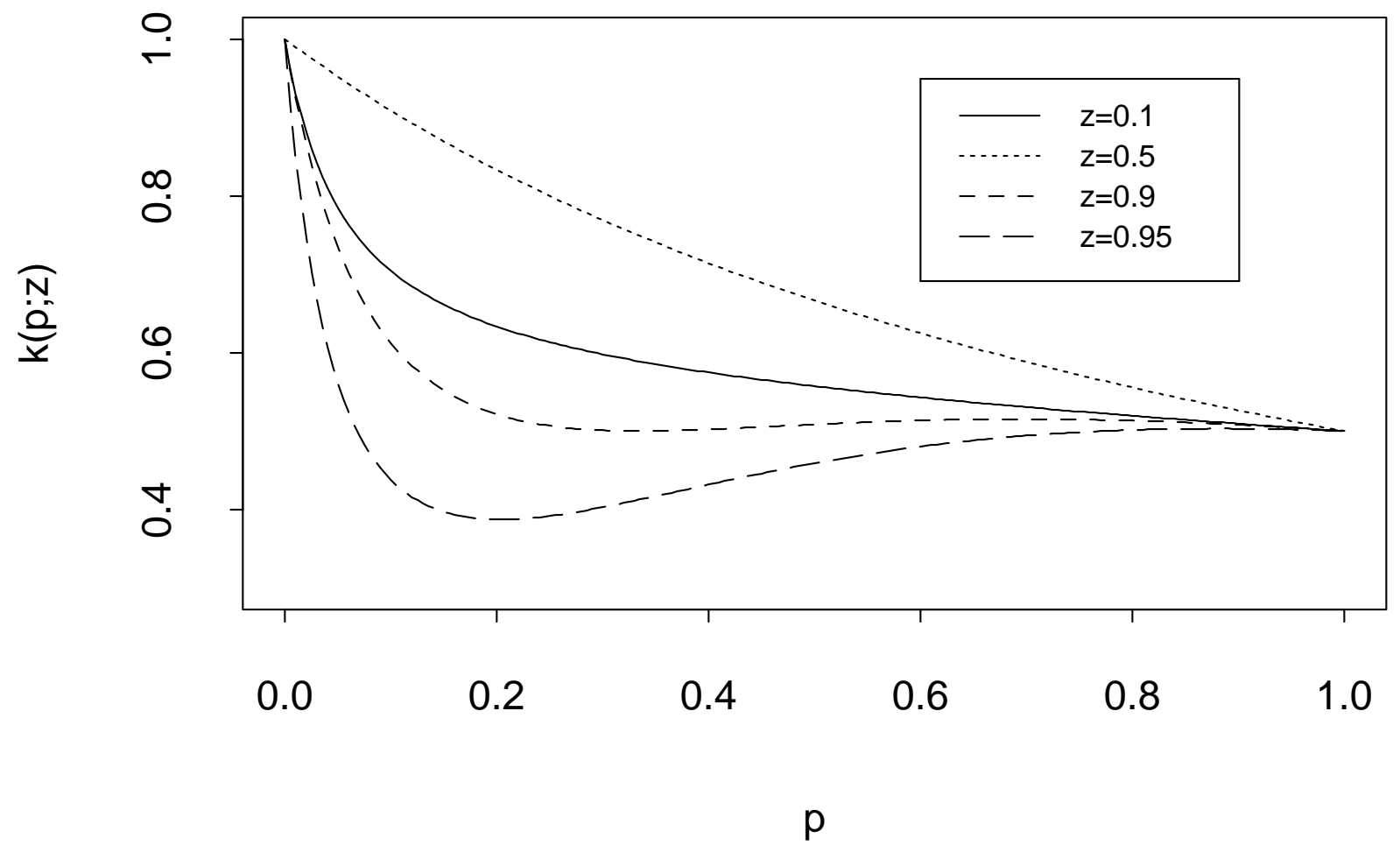

Figure I

\section{A. Correlation and Inflated Grades}

In this subsection, we examine how the degree of correlation of states across the two schools affects their equilibrium probabilities of inflating the grades. Positive correlation in the quality of the student bodies across schools may arise because general economic conditions (e.g., business cycles, the size of the skills premium) affect the decision to enter college, or because the overall environment of teaching and research affects the value-added of the education process. On the other hand, competition by schools for the same cohort of good students may result in a negative correlation of states.

Are schools more like to inflate when states become more (positively or negatively) correlated?

We restrict our attention to the case $\gamma>\frac{1}{2}$, so that an inflationary semi-pooling equilibrium always exists. The condition for the equilibrium probability $p^{*}$ of inflating the grades is $k\left(p^{*} ; z\right)=\gamma$. If $p^{*}$ is unique, then $\partial p^{*} / \partial z$ has the same sign as $\partial k / \partial z$. If there are multiple solutions to the equilibrium condition, then the same conclusion applies when 
$p^{*}$ is the largest or the smallest equilibrium solution (Milgrom and Roberts [1994]). A direct calculation yields:

$$
\frac{\partial k(p ; z)}{\partial z}=\frac{\left(1+(3-2 z) p+2 z p^{2}\right)(1-p) p(1-2 z)}{\left(z+2(1-z)+z p^{2}\right)^{2}(1-z+z p)^{2}} .
$$

Thus, $\partial k(p ; z) / \partial z$ has the same sign as $1-2 z$. If $z \leq \frac{1}{2}$, a decrease in $z$ (increased negative correlation) shifts the $k(p)$ curve down and reduce the equilibrium probability of grade exaggeration. If $z \geq \frac{1}{2}$, an increase in $z$ (increased positive correlation) also shifts the $k(p)$ curve down and reduce grade exaggeration. See Figure I. Therefore, schools' equilibrium probability of inflating the grades reaches a maximum at $z=\frac{1}{2}$, when the two schools have independent states. Greater (positive or negative) correlation in states across the two schools serves to constrain grade exaggeration.

Correlation constrains grade exaggeration because it reduces the probability that each school fools the market with easy grades. A greater positive correlation has two opposing effects: it improves the credibility of bilateral easy grades (increases $q\left(F_{1} \mid e_{1}, e_{2}\right)$ for school 1 ) and reduces the credibility of unilateral easy grades (decreases $q\left(F_{1} \mid e_{1}, t_{2}\right)$ for school 1 ). However, a deciding third effect of an increase in positive correlation is that it becomes more likely for employers to observe $t_{2}$ under state $U_{1}$. This makes fooling the market more difficult because under positive correlation unilateral easy grading is not as credible as bilateral easy grading $\left(q\left(F_{1} \mid e_{1}, t_{2}\right)<q\left(F_{1} \mid e_{1}, e_{2}\right)\right.$ when $\left.z>\frac{1}{2}\right)$. A greater negative correlation also makes it more difficult to fool the market, but for the opposite reason: it makes it less likely for employers to observe $t_{2}$ under $U_{1}$, and under negative correlation unilateral easy grades is the more credible signal.

The case of independent states $\left(z=\frac{1}{2}\right)$ is equivalent to the single-school case analyzed in Section III. It might appear against one's intuition that grade exaggeration is generally less serious with two schools than with a single school. But in our framework schools do not directly compete with one another in placements or in any other way. The only strategic interaction between schools comes from the underlying inference problem faced by the labor market when the schools have correlated states. The problem of inflated grades is less serious with two schools because it is harder to fool the market when there are two signals available instead of one. 


\section{B. Strategic Interactions}

We know from the single-school case that grade exaggeration at an isolated school can result from a number of exogenous changes, such as a smaller $R$, a greater $\pi$, or a greater $\phi_{F} / \phi_{U}$. How do changes in one school's grading policy affect other schools? How does the new equilibrium compare with the one before the changes took place? The answers depend on whether inflationary grading policies at different schools are strategic complements or strategic substitutes.

For each school $i=1,2$, denote $i$ 's equilibrium probability of inflating the grades by $p_{i}^{*}$. The indifference condition for school 1 is

$$
k_{1}\left(p_{1}^{*}, p_{2}^{*}\right)=\gamma_{1}
$$

where $\gamma_{1}$ is defined as in equation (6) using the parameter values for school 1 . The function $k_{1}$ is given by

$$
k_{1}\left(p_{1}, p_{2}\right)=\left(1-z+z p_{2}\right) q\left(F_{1} \mid e_{1}, e_{2}\right)+z\left(1-p_{2}\right) q\left(F_{1} \mid e_{1}, t_{2}\right)
$$

where $q\left(F_{1} \mid e_{1}, e_{2}\right)$ and $q\left(F_{1} \mid e_{1}, t_{2}\right)$ are given in equation (12). We will think of equation (14) as defining the "reaction function" $p_{1}^{*}\left(p_{2}\right)$ for school 1 . For any $\gamma_{1}>\frac{1}{2}$, we have $k_{1}(0,0)=1>\gamma_{1}$, implying $p_{1}^{*}(0)>0$. Similarly, $k_{1}(1,1)=\frac{1}{2}<\gamma_{1}$, which implies $p_{1}^{*}(1)<1$. The same conclusion holds for school 2. Therefore, for any $\gamma_{1}, \gamma_{2} \in\left(\frac{1}{2}, 1\right)$, there exists at least one inflationary semi-pooling equilibrium.

The slope of the reaction function $p_{1}^{*}\left(p_{2}\right)$ is

$$
\frac{d p_{1}^{*}}{d p_{2}}=-\frac{\partial k_{1} / \partial p_{2}}{\partial k_{1} / \partial p_{1}}
$$

For any $z$, we have:

$$
\frac{\partial k_{1}}{\partial p_{1}}=\left(1-z+z p_{2}\right) \frac{\partial q\left(F_{1} \mid e_{1}, e_{2}\right)}{\partial p_{1}}+z\left(1-p_{2}\right) \frac{\partial q\left(F_{1} \mid e_{1}, t_{2}\right)}{\partial p_{1}}<0
$$

since both $q\left(F_{1} \mid e_{1}, e_{2}\right)$ and $q\left(F_{1} \mid e_{1}, t_{2}\right)$ are decreasing functions of $p_{1}$. Also,

$$
\begin{aligned}
\frac{\partial k_{1}}{\partial p_{2}} & =z\left(q\left(F_{1} \mid e_{1}, e_{2}\right)-q\left(F_{1} \mid e_{1}, t_{2}\right)\right)+\left(1-z+z p_{2}\right) \frac{\partial q\left(F_{1} \mid e_{1}, e_{2}\right)}{\partial p_{2}} \\
& =\frac{p_{1}(1-2 z)^{2}}{\left(z+(1-z)\left(p_{1}+p_{2}\right)+z p_{1} p_{2}\right)^{2}\left(1-z+z p_{1}\right)}>0 .
\end{aligned}
$$


It follows that $d p_{1}^{*} / d p_{2}>0$, and $p_{1}$ and $p_{2}$ are strategic complements. ${ }^{14}$

An increased probability of inflating the grades by school 2 makes the event of both schools having easy grades more likely. Under positive correlation, this helps school 1 fool the market, because having easy grading at both schools is a stronger signal for state $F_{1}$ than having easy grading at school 1 only $\left(q\left(F_{1} \mid e_{1}, e_{2}\right)>q\left(F_{1} \mid e_{1}, t_{2}\right)\right.$ when $\left.z>\frac{1}{2}\right)$. But the second effect is that it changes the market estimate of state $F_{1}$ when both schools have easy grades. Under positive correlation, an increase in $p_{2}$ lowers $q\left(F_{1} \mid e_{1}, e_{2}\right)$ because the market will put more weight on the event that both schools are inflating their grades. This makes it more difficult for school 1 to fool the market. The first effect dominates the second effect under positive correlation, and the net effect of an increase in $p_{2}$ is an increase in $k_{1}\left(p_{1}, p_{2}\right)$. Under negative correlation, the sign as well as the relative magnitude of these two effects are reversed, so the net result is still $\partial k_{1} / \partial p_{2}>0$.

Therefore, under both positive and negative correlation, it is easier for school 1 to fool the market with inflated grades when there is an increased use of grade exaggeration by school 2. The result is that grade exaggeration is a supermodular game between the two schools, suggesting the following illustrative adjustment process. Suppose that a school does not adjust its grading policy in response to the other school instantaneously. Instead, let $p_{i}$ be the optimal response to $p_{j}(i \neq j)$ with a one-period lag, as in a Cournot adjustment process. When there is a decrease in $\gamma_{2}$ (resulting from, say, a decrease in school 2's concern $R_{2}$ for its good students) while $\gamma_{1}$ remains unchanged, school 2 will raise its probability of inflating the grades in response to this change. As $p_{2}$ rises, even though there is no change in the underlying parameters at school 1, school 1 finds that it is easier to fool the market into believing that its state is favorable when it gives easy grades. So $p_{1}$ rises in the next period. The increase in $p_{1}$ prompts $p_{2}$ to rise even further in the subsequent period, and so on until the process converges to a new equilibrium level. When adjustments are not instantaneous, therefore, a one-time change in exogenous parameters can produce a series of endogenous changes in grading policies that resemble an inflationary trend. In other words, strategic interactions between the schools provide a "propagation mechanism" through which grade exaggeration is transmitted from one school to another.

14 If the states in the two schools are uncorrelated, $p_{1}$ and $p_{2}$ are strategically independent. 


\section{Signaling By Many Schools}

The probability model we use in Section IV is suitable for studying how the degree of correlation in student quality across two schools affects grade exaggeration; it is less flexible for studying the case of more than two schools. Extending the analysis to signaling by many schools is useful because it can provide comparative statics and limit results for changes in the number of schools in the education system.

We build a stylized model with common shocks and idiosyncratic shocks. ${ }^{15}$ Let there be two aggregate states, $F$ and $U$, with prior probabilities $\theta$ and $1-\theta$, respectively. In state $U$, each school $i(i=1, \ldots, N)$ is in state $U_{i}$ with probability 1 . They all have a student body with a small proportion $\phi_{U}$ of good students. In state $F$, each school $i$ has an independent probability $\pi$ of reaching state $F_{i}$ (with a greater proportion $\phi_{F}$ of good students) and a probability $1-\pi$ of reaching state $U_{i}$. Each school knows its own state, but not those of other schools. ${ }^{16}$

Consider an inflationary semi-pooling equilibrium, in which each school $i$ chooses easy grading $e_{i}$ with probability 1 in state $F_{i}$ and with probability $p$ in state $U_{i}$. As in Sections III and IV, equilibrium is characterized by the condition $k(p ; N)=\gamma$, where $\gamma$ is a function of the exogenous parameters as defined in equation (6), and the function $k(p ; N)$ is school $i$ 's assessment of how easy it is for it to "fool" the market into believing that the state is $F_{i}$ when $e_{i}$ is observed. We proceed to derive an explicit expression for $k(p ; N)$.

If the aggregate state is favorable $(F)$, then the total probability that any one school will choose easy grading is $\pi+(1-\pi) p$. If the aggregate state is unfavorable $(U)$, then the probability that any one school will choose easy grading is just $p$. Conditional on state $U_{i}$, the probability of the aggregate state being $F$ is given by

$$
\mu=\frac{\theta(1-\pi)}{\theta(1-\pi)+1-\theta} .
$$

\footnotetext{
15 This type of model necessarily implies positive correlation across any two schools. It is also possible to construct models with negative correlation with three or more schools. For example, if there are $N$ schools in total and the state of a fixed number $Y$ of the $N$ schools is $F$ and the state of the rest $N-Y$ schools is $U$, then the states of any two individual schools are negatively correlated. The analysis in this model is similar to the model presented below with positive correlation.

16 This model includes the single-school case analyzed before as a special case, with $N=1$ and $\theta=1$. If we let $N=2, \pi=z, \theta=1 /(2 z)$, then it becomes the two-school model with positive correlation.
} 
Therefore, if school $i$ chooses easy grading in state $U_{i}$, its assessment of the probability that the market observes a total of $l(l=1, \ldots, N)$ schools with easy grades is

$$
\operatorname{Pr}\left[l \mid U_{i}\right]=\mu b(N-1, l-1, \pi+(1-\pi) p)+(1-\mu) b(N-1, l-1, p),
$$

where $b(\cdot, \cdot, \cdot)$ denotes the binomial probability function (i.e., $b(N, l, p)$ is the probability of observing $l$ successes out of $N$ Bernoulli trials with independent probability of success $p)$. Let $q\left(F_{i} \mid l\right)$ be the market's assessment of the probability of state $F_{i}$ when there are $l$ schools (including school $i$ ) that chooses easy grading. Then, applying Bayes' rule, we have

$$
q\left(F_{i} \mid l\right)=\frac{\theta b(N, l, \pi+(1-\pi) p)}{\theta b(N, l, \pi+(1-\pi) p)+(1-\theta) b(N, l, p)} \frac{\pi}{\pi+(1-\pi) p} .
$$

The first fraction on the right-hand-side is the probability that the aggregate state is $F$ given $l$ schools with easy grades; the second fraction is the probability that school $i$ is in the favorable state given that the aggregate state is favorable. The total probability of fooling the market into believing the state is $F_{i}$ is given by

$$
k(p ; N)=\sum_{l=1}^{N} \operatorname{Pr}\left[l \mid U_{i}\right] q\left(F_{i} \mid l\right) .
$$

The function $k(p ; N)$ is continuous with $k(0 ; N)=1$ and $k(1 ; N)=\theta \pi$. Therefore for any finite $N$, an inflationary semi-pooling equilibrium exists if $\gamma>\theta \pi$. One can also show that an inflationary pooling equilibrium exists if $\gamma \leq \theta \pi$. In Appendix B we show that $k(p ; N+1)<k(p ; N)$ for all $p \in(0,1)$. The presence of more schools, and hence more independent signals, makes it more difficult for any individual school to "fool" the market. Consequently, a larger $N$ causes the equilibrium probability $p^{*}$ of grade exaggeration to fall.

If an increase in $N$ reduces grade exaggeration, will inflated grades disappear when there are arbitrarily many schools? In other words, will the equilibrium probability of grade exaggeration converge to 0 , or will it converge to a limit bounded away from 0 ? When $N$ is arbitrarily large, in a semi-pooling equilibrium, the proportion of schools with easy grades is $p$ in the aggregate state $U$, and is $\pi+(1-\pi) p$ in the aggregate state $F$. Thus, the market can perfectly infer the aggregate state from the proportion of schools 
with easy grades. When school $i$ observes that its own state is unfavorable $U_{i}$, it infers that there is a probability $\mu$ that the aggregate state is favorable. In that case, the market observes a fraction $\pi+(1-\pi) p$ of the schools with easy grades, knowing that only a fraction $\pi$ of the schools are truly in the favorable state. Therefore, the market assigns a probability $\operatorname{Pr}\left[F_{i} \mid F\right]=\pi /(\pi+(1-\pi) p)$ that the student mix in school $i$ is favorable. The school also perceives that with probability $1-\mu$, the aggregate state is unfavorable. In that case, the market can tell with certainty that the aggregate state is unfavorable, and assigns a probability $\operatorname{Pr}\left[F_{i} \mid U\right]=0$ that the student mix in school $i$ is favorable. Thus, the probability that school $i$ can fool the market into believing that its student mix is favorable by inflating its grades is

$$
k(p ; \infty)=\mu \operatorname{Pr}\left[F_{i} \mid F\right]+(1-\mu) \operatorname{Pr}\left[F_{i} \mid U\right]=\frac{\mu \pi}{\pi+(1-\pi) p} .
$$

For $N$ arbitrarily large, the condition for an inflationary semi-pooling equilibrium is given by the equation $k(p ; \infty)=\gamma$. The function $k(p ; \infty)$ is decreasing in $p$, with $k(0 ; \infty)=\mu$ and $k(1 ; \infty)=\mu \pi$. The same arguments as in Proposition 1 establish:

Proposition 4. For $N$ arbitrarily large, an inflationary semi-pooling equilibrium exists if $\gamma \in(\mu \pi, \mu)$.

Thus, inflated grades can persist even in the limit as the number of schools grows indefinitely. However, if $\gamma \geq \mu$, the probability of fooling the market for each school $i$ in state $U_{i}$ is lower than what it takes for it to be indifferent between $e_{i}$ and $t_{i}$, even if in equilibrium no school inflates grades. We then have a separating equilibrium, with honest grading by each school. ${ }^{17}$ Therefore, an increase in number of schools can potentially eliminate grade exaggeration when $\gamma$ is large enough. ${ }^{18}$

17 For any finite $N$, an inflationary semi-pooling equilibrium exists even in this case. However, the probability of grade exaggeration is arbitrarily close to zero when $N$ is large.

18 If $\gamma$ is relatively small, an inflationary pooling equilibrium may occur. In such an equilibrium, the observed proportion of schools with easy grades is in both state $F$ and state $U$, so the market cannot distinguish the two aggregate states. The competitive wage offer for $A$-students from any school with easy grades is then $w(A \mid F, e)=\theta \pi \omega_{G}+(1-\theta \pi) \underline{\omega}$. The probability of fooling the market with inflated grades is $\theta \pi$, instead of $k(1 ; \infty)=\mu \pi$. This discontinuity in the probability of fooling the market at $p=1$ is due to the fact that the market is able to distinguish the two aggregate states except when $p=1$. The result is that there exists an inflationary pooling equilibrium if and only if $\gamma \leq \theta \pi$. 


\section{Vi. Curbing Inflated Grades}

If grade exaggeration garbles the signaling value of grades and reduces the welfare of the school, are there feasible ways to curb it? In this section, we use our model to discuss two methods that have been proposed (and adopted by some schools) to tame grade exaggeration.

Some universities have experimented with putting two grades on student transcripts: the student's individual grade and the class average grade (The Economist, April 12, 2001). The idea is to provide employers with more information to evaluate the meaning of any individual job applicant's grades. If employers have static or adaptive expectations about a school's grading policy, such a move can reduce their "grade illusion" and hence remove the school's temptation to inflate grades. Although we do not dispute the value of providing more information on transcripts, we doubt if this can solve the problem of inflated grades. Schools inflate their grades because sometimes easy grades are justified. A high class average grade does not immediately imply lax grading; perhaps the school just happens to have a lot of good students. In our model, employers can perfectly observe the class average grade (i.e., the percentage of $A$ 's and $B$ 's), yet equilibrium grade exaggeration persists.

Another strategy to tame grade exaggeration is to assess students strictly on the basis of ranks. Some universities, for example, fix the proportion of their students graduating with honors (The New York Times, May 22, 1988), so that a good student may not receive honors if his peers are outstanding. ${ }^{19}$ This kind of policy requires commitment, since we have shown in Section III that tough grading is not an equilibrium in our signaling model. Nevertheless, committing to a fixed proportion of $A$ 's is a lot easier than committing to honest grading. The latter requires varying the proportion of $A$ 's with the underlying state, which is unverifiable. The former only requires the school to give the same proportion of A's every year. The school's reputation can suffer if it breaks its commitment.

19 In the case of stock recommendations, some investment banks are experimenting with committing themselves to some fixed percentage of "sell" recommendations. 
Committing to a fixed proportion of $A$ 's is not a first-best policy, since the proportion of good students changes from year to year. It is therefore interesting to see whether the commitment policy is better than the equilibrium policy with grade exaggeration from the school's perspective. Let $V(\phi)$ be the school's payoff when it commits to giving a fixed proportion $\phi$ of $A$ grades. Naturally, $\phi$ lies between $\phi_{U}$ and $\phi_{F}$. Under this policy, the competitive wage for $A$-students is

$$
w(A)=\pi \omega_{G}+(1-\pi)\left(\frac{\phi_{U}}{\phi} \omega_{G}+\left(1-\frac{\phi_{U}}{\phi}\right) \omega_{M}\right)
$$

The wage for $B$-students is

$$
w(B)=\pi\left(\left(1-\frac{1-\phi_{F}}{1-\phi}\right) \omega_{G}+\frac{1-\phi_{F}}{1-\phi} \omega_{M}\right)+(1-\pi) \omega_{M}
$$

Then,

$$
\begin{aligned}
V(\phi)=\pi( & \left.R \phi w(A)+R\left(\phi_{F}-\phi\right) w(B)+\left(1-\phi_{F}\right) w(B)\right) \\
& +(1-\pi)\left(R \phi_{U} w(A)+\left(\phi-\phi_{U}\right) w(A)+(1-\phi) w(B)\right) .
\end{aligned}
$$

Observe that as $\phi$ increases, both $w(A)$ and $w(B)$ decrease but the coefficient of $w(A)$ in $V(\phi)$ increases, so there are two opposing effects. A few steps of calculations show that $V^{\prime}(\phi)$ has the same sign as

$$
\frac{\pi}{1-\pi}-\frac{\phi_{U}}{\phi} \frac{1-\phi}{1-\phi_{F}}
$$

If $V(\phi)$ has a stationary point in the range $\left(\phi_{U}, \phi_{F}\right)$, the stationary point is a local minimum. It follows that the optimal commitment level $\phi$ is either $\phi_{U}$ or $\phi_{F}$.

Would a commitment to tough grading or easy grading improve on the school's equilibrium payoff? To answer the question, we first note that when the school is in an inflationary pooling equilibrium, its payoff is just $V\left(\phi_{F}\right)$. Also, the payoff in an inflationary semi-pooling equilibrium is greater than $V\left(\phi_{F}\right)$, because in such equilibrium the school is indifferent between easy grading and tough grading in state $U$, with an equilibrium wage to $A$-students higher than that with a commitment to $\phi_{F}$. Thus, we only need to compare the equilibrium payoff $V^{*}$ to $V\left(\phi_{U}\right)$. It can be easily shown that $V^{*}<V\left(\phi_{U}\right)$ if and only if

$$
(1-\pi)(1-q(F \mid e)) \frac{\phi_{U}}{\phi_{F}}-\pi^{2} \frac{1-\phi_{F}}{1-\phi_{U}}>(q(F \mid e)-\pi)\left(\pi+\frac{1}{R-1}\right) .
$$


In an inflationary pooling equilibrium $q(F \mid e)=\pi$, so the above condition becomes

$$
(1-\pi)^{2} \frac{\phi_{U}}{\phi_{F}}>\pi^{2} \frac{1-\phi_{F}}{1-\phi_{U}}
$$

In an inflationary semi-pooling equilibrium, using the definition of $q(F \mid e)$ (equation (2)), we have instead:

$$
\frac{\phi_{F}}{(R-1) \phi_{U}+\phi_{F}}>\left(1-\frac{1}{R}\right)\left(\pi \frac{1-\phi_{F}}{1-\phi_{U}}+1-\pi\right)
$$

In either type of equilibrium, it is possible that commitment to tough grading makes the school strictly better off. ${ }^{20}$ In a pooling equilibrium, grade exaggeration is at the highest level. If this results from the high prior probability of the favorable state, then commitment to tough grading can hurt the school: an increase in $\pi$ tends to reverse (15). In fact, condition (15) cannot be satisfied if $\pi$ is sufficiently great. Intuitively, commitment to tough grading can be too costly because it often forces the school to give $B$ 's to some of its good students. In a semi-pooling equilibrium, grade exaggeration is limited due to a lower likelihood of the favorable state or a greater concern for good students. The same two factors tend to reverse the inequality of equation (16). In this case the benefit to the school from the commitment to tough grading is small relative to its cost, and the school will not make such commitment even if it is credible.

Given that schools may not have the incentive to self-discipline, external inducements may be necessary to curb grade exaggeration, which would be worthwhile if, for example, sorting of workers is important for economic efficiency. One way of discouraging grade exaggeration is to align the interest of the school more closely with the welfare of its good students (increase $R$ in our model). This may be achieved by tying a school's funding more closely to the long-term labor market performance of its students. Greater tax benefits for alumni donations (assuming that the marginal propensity to contribute increases with income) or increased public funding for schools to reward outstanding achievements of their alumni will make it more in the interest of the school to ensure that the abilities of good students are duly recognized by the market. Over the long run, this can encourage more honest grading in schools.

\footnotetext{
20 Conditions (15) and (16) coincide when $\pi=\gamma$, when they are most likely to be satisfied.
} 


\section{Summary AND Discussion}

If grades convey information about the relative merits of students, why would schools have the incentive to adopt overly liberal grading standards? The answer we propose is that employers cannot fully distinguish between a situation in which a school is giving lots of easy $A$ 's and a situation in which the school simply has many good students. Indeed, because a school with more good students has an incentive to give more $A$ 's, employers use a liberal grading curve as a signal to infer high overall student quality in the school. This does not imply that grades will shoot to the roof, since schools also care about preserving the value of $A$ 's for its good students. We identify an equilibrium level of grade exaggeration in this paper, and are able to show that honest grading or other kinds of grading policies (such as grade deflation) are not reasonable equilibrium outcomes in our setting.

Inflated grades help mediocre students at the expense of good students. In a manner similar to the central bank dilemma (Kydland and Prescott [1977]), schools would gain if they could commit to an honest grading policy. Our comparative statics results show that schools less concerned with its good students or schools with a higher chance of having a large fraction of good student are more likely to inflate the grades. In an environment with multiple schools, we show that grade exaggeration by one school makes it easier for another school to fool the market with inflated grades. Thus inflationary grading policies are strategic complements, and this provides a channel that makes grade exaggeration contagious. Nevertheless the availability of signals from other schools does reduce the equilibrium level of grade exaggeration in our setup.

The problem of inflated grades is multi-faceted, and we do not pretend to have covered all grounds in this paper. Our model is an equilibrium model with little dynamics. It explains why grades are too high, but aside from our comparative statics results and our discussion of the Cournot adjustment process, it says little about why they keep rising. One possible approach to explicitly model the dynamics of grade inflation is to introduce ambiguity and reputation effects as in central bank models of monetary inflation (Cukierman and Meltzer [1986]; Rogoff [1987]). We believe that the tradeoff between 
helping mediocre students and hurting good students, as well as the signaling constraints needed to sustain equilibrium, will provide the basic building blocks of a dynamic model.

In this paper, competitive interaction among schools is restricted to their signaling strategies. But schools compete in other dimensions too. For example, if there are rents in a fixed number of desirable positions, good students may benefit disproportionately from a tight grading policy in the competition for these positions. Furthermore, since grading policies affect the relative well-being of different types of students, they have implications for the competition for incoming students and for the sorting of students by schools as well. These interesting questions have not been addressed in our present work.

Finally, we have not looked into issues related to the role of grades as motivator. A paper by Costrell [1994] studies how educational standards affect students' incentives to exert effort. In that paper, lower standards (grade exaggeration) can reduce the effort of good students while raising the effort of the marginal students. Incorporating student effort into our model probably reinforces our conclusion about the welfare effects of grade exaggeration. We also note that students may try to obtain better grades by exerting pressure on their professors. This aspect of the problem of inflated grades is particularly interesting when studied in the context of stock recommendations and audit reports. To what extent can companies offer economic inducements that alter the information disseminated by stock analysts and auditors? Can independent information providers survive in this kind of environment? We hope our signaling model of inflated grades will be a first step toward addressing this type of issues.

\section{APPENDIX}

\section{A. Equilibrium Selection}

In this appendix we rule out the existence of any equilibrium other than the inflationary equilibria in the single-school setting of Section III.

One of the two possible separating equilibria - truthful grading - can be ruled out immediately. If the school's grading outcome truthfully reflects the ability mix of its students, then upon observing easy grading, the market would conclude that the state 
is favorable, which would prompt the school to inflate grades when the state is actually unfavorable.

Next, we rule out the "reverse separating equilibria" (where the school chooses $t$ in state $F$ and $e$ in state $U$ ), the "double-pooling equilibria" (where it randomizes between $e$ and $t$ in both states), and the "reverse semi-pooling equilibria" (where it randomizes between $t$ and $e$ in state $F$ and chooses $e$ in state $U$, or it randomizes between $t$ and $e$ in state $U$ and chooses $t$ in state $F$ ). To have any one of these three types of equilibria, the school must (i) weakly prefer $e$ to $t$ in state $U$; and (ii) weakly prefer $t$ to $e$ in state $F$. For this to be true, the sign of the single-crossing condition (1) has to be reversed. In other words, we require $(R-1)\left(\phi_{F}-\phi_{U}\right)(w(A \mid e)-w(B \mid t)) \leq 0$, which implies that $w(B \mid t) \geq w(A \mid e)$. Furthermore, since the school chooses $e$ in state $U$ with positive probability under the proposed equilibria, we have $w(A \mid e)<\omega_{G}$. Similarly, since the school chooses $t$ in state $F$ with positive probability under the proposed equilibria, we have $w(B \mid t)>\omega_{M}$. These three inequalities imply that

$R \phi_{U} w(A \mid e)+\left(\phi_{F}-\phi_{U}\right) w(A \mid e)+\left(1-\phi_{F}\right) \omega_{M}<R \phi_{U} \omega_{G}+\left(\phi_{F}-\phi_{U}\right) w(B \mid t)+\left(1-\phi_{F}\right) w(B \mid t)$,

which contradicts the assumption that the school weakly prefers easy grading to tough grading in the unfavorable state.

Next, we rule out "deflationary semi-pooling equilibria", where the school randomizes between $t$ and $e$ in state $F$ and chooses $t$ in state $U$. Such an equilibrium does not directly contradict the single-crossing condition, because by equation (1) the school's indifference between $t$ and $e$ in state $F$ implies its strict preference for $t$ in state $U$ as long as $w(A \mid e)>$ $w(B \mid t)$, which is true in equilibrium as $w(A \mid e)=\omega_{G}$. However, any such equilibrium can be ruled out because the school cannot be indifferent in state $F$. To see this, note that in equilibrium $w(A \mid t)=w(A \mid e)=\omega_{G}$ and $w(B \mid e)=\omega_{M}$. Further,

$$
w(B \mid t) \leq \pi\left(\frac{\phi_{F}-\phi_{U}}{1-\phi_{U}} \omega_{G}+\frac{1-\phi_{F}}{1-\phi_{U}} \omega_{M}\right)+(1-\pi) \omega_{M}
$$

with equality only if the school chooses $t$ with probability 1 in state $F$. The above conditions imply that for the school to be indifferent between $t$ and $e$, one would need

$$
\frac{R\left(\phi_{F}-\phi_{U}\right)}{R\left(\phi_{F}-\phi_{U}\right)+\left(1-\phi_{F}\right)} \leq \frac{\pi\left(\phi_{F}-\phi_{U}\right)}{1-\phi_{U}}
$$


which is impossible because the left-hand-side of the above inequality is greater than $\left(\phi_{F}-\phi_{U}\right) /\left(1-\phi_{U}\right)$.

Finally, consider a "deflationary pooling equilibrium," in which the school chooses tough grading in both states. In such an equilibrium $A$-students get $w(A \mid t)=\omega_{G}$ and $B$-students get

$$
w(B \mid t)=\pi\left(\frac{1-\phi_{F}}{1-\phi_{U}} \omega_{M}+\left(1-\frac{1-\phi_{F}}{1-\phi_{M}}\right) \omega_{G}\right)+(1-\pi) \omega_{M} .
$$

If a deviation to $e$ is observed, $B$-students get $\omega_{M}$, and the wage $w(A \mid e)$ for $A$-students lies between $\underline{\omega}$ and $\omega_{G}$. This type of pooling equilibria always exist because in each state the school strictly prefers $e$ to $t$ if $w(A \mid e)$ is sufficiently close to $\underline{\omega}$. But it is sustained by the market belief that state $F$ is sufficiently unlikely so that the wage $w(A \mid e)$ paid to $A$-students is too low to make such deviation profitable. This belief is out of the equilibrium path, and therefore unrestricted by the solution concept of perfect Bayesian equilibrium adopted here. However, such belief is unreasonable, and the deflationary pooling equilibrium can be ruled out by the standard refinement criterion D1 (Banks and Sobel's [1987]). To show this, it suffices to establish that the lowest wage $w(A \mid e)$ for $A$-students that induces a deviation to $e$ is higher in state $U$ than in state $F$. This condition can be written as:

$$
\begin{aligned}
& \frac{R \phi_{U} \omega_{G}+\left(\phi_{F}-\phi_{U}\right) w(B \mid t)+\left(1-\phi_{F}\right)\left(w(B \mid t)-\omega_{M}\right)}{R \phi_{U}+\phi_{F}-\phi_{U}} \\
> & \frac{R \phi_{U} \omega_{G}+R\left(\phi_{F}-\phi_{U}\right) w(B \mid t)+\left(1-\phi_{F}\right)\left(w(B \mid t)-\omega_{M}\right)}{R \phi_{U}+R\left(\phi_{F}-\phi_{U}\right)} .
\end{aligned}
$$

One can verify that the above always holds. It ensures that the set of wage offers that would induce deviation to easy grading under state $F$ strictly contains the set of wage offers that would induce deviation under state $U$. Thus, the school is "infinitely more likely" to make such deviation in state $F$ than in state $U$. When deviation to easy grading is observed, the market should then believe that the state is $F$. This belief will not support a deflationary pooling equilibrium, as the school would indeed deviate in state $F$.

\section{B. Decreasing Probability of Fooling the Market}

In this appendix, we prove that in the model of many schools of Section $\mathrm{V}$, the probability of fooling the market falls as the number of schools increases. That is, $k(p ; N)>k(p ; N+1)$ for all $p \in(0,1)$. 
Denote $x=\pi+(1-\pi) p>p$. Let

$$
g(l ; N)=\frac{\mu x^{l-1}(1-x)^{N-l}+(1-\mu) p^{l-1}(1-p)^{N-l}}{\theta x^{l}(1-x)^{N-l}+(1-\theta) p^{l}(1-p)^{N-l}} \frac{\theta \pi}{\pi+(1-\pi) p} .
$$

We have,

$$
\begin{aligned}
& k(p ; N)-k(p ; N+1) \\
= & \sum_{l=1}^{N}\left(\begin{array}{c}
N-1 \\
l-1
\end{array}\right) x^{l}(1-x)^{N-l} g(l ; N) \\
& -\sum_{l=1}^{N+1}\left(\begin{array}{c}
N \\
l-1
\end{array}\right) x^{l}(1-x)^{N-l+1} g(l ; N+1) .
\end{aligned}
$$

Using the identity

$$
\left(\begin{array}{c}
N \\
l-1
\end{array}\right)=\left(\begin{array}{c}
N-1 \\
l-1
\end{array}\right)+\left(\begin{array}{c}
N-1 \\
l-2
\end{array}\right)
$$

for $l=2, \ldots, N$, we can rewrite equation (17) as

$$
\begin{aligned}
& k(p ; N)-k(p ; N+1) \\
= & \sum_{l=1}^{N}\left(\begin{array}{c}
N-1 \\
l-1
\end{array}\right) x^{l}(1-x)^{N-l}(g(l ; N)-(1-x) g(l ; N+1)) \\
& -\sum_{l=2}^{N+1}\left(\begin{array}{c}
N-1 \\
l-2
\end{array}\right) x^{l}(1-x)^{N-l+1} g(l ; N+1) \\
= & \sum_{l=1}^{N}\left(\begin{array}{c}
N \\
l
\end{array}\right) x^{l}(1-x)^{N-l}(g(l ; N)-(1-x) g(l ; N+1)-x g(l+1 ; N+1)) .
\end{aligned}
$$

Tedious calculation gives

$$
\begin{aligned}
& g(l ; N)-(1-x) g(l ; N+1)-x g(l+1 ; N+1) \\
= & \frac{1}{a} \frac{\theta \pi}{\pi+(1-\pi) p} \mu \theta(1-\theta)(p-x)^{2} x^{l-1}(1-x)^{N-l} p^{2 l-1}(1-p)^{2(N-l)} \\
& \times\left(\frac{x(1-\mu)}{\mu}-\frac{p(1-\theta)}{\theta}\right),
\end{aligned}
$$

where

$$
\begin{aligned}
a= & \left(\theta x^{l}(1-x)^{N-l}+(1-\theta) p^{l}(1-p)^{N-l}\right)\left(\theta x^{l}(1-x)^{N-l+1}+(1-\theta) p^{l}(1-p)^{N-l+1}\right) \\
& \times\left(\theta x^{l+1}(1-x)^{N-l}+(1-\theta) p^{l+1}(1-p)^{N-l}\right) .
\end{aligned}
$$

Since $(1-\mu) / \mu>(1-\theta) / \theta$ and since $x>p$, the expression in (18) is positive. Therefore $k(p ; N)>k(p ; N+1)$. 


\section{REFERENCE}

Anglin, Paul M.; and Meng, Ronald. "Evidence on Grades and Grade Inflation at Ontario's Universities," Canadian Public Policy 26, September 2000: 361-368.

Banks, J.; and Sobel, J. "Equilibrium Selection in Signaling Games," Econometrica 55, 1987: 647-662.

The Boston Globe. "Matters of Honor," October 7-8, 2001.

Capozza, Dennis R. "Student Evaluations, Grades and Learning in Economics," Western Economic Journal 11(1), March 1973.

Carney, P.; Isakson, R.L.; and Ellsworth. "An Exploration of Grade Inflation and Some Related Factors in Higher Education," College and University 53, 1978: 217-230.

Chronicle of Higher Education. "Dartmouth college Takes a Swipe at Grade Inflation," November 16, 1994.

Costrell, Robert M. "A Simple Model of Educational Standards," American Economic Review 84, September 1994: 956-971.

Crawford, Vincent; and Sobel, Joel. "Strategic Information Transmission," Econometrica 50, 1982: 1431-1451.

Cukierman, Alex; and Meltzer, Allan H. "A Theory of Ambiguity, Credibility, and Inflation under Discretion and Asymmetric Information," Econometrica 54, November 1986: 1099-1128.

The Daily Telegraph. "Cambridge to Demand A-level Percentage Scores," August 22, 2004.

Dickson, V. "An Economic Model of Faculty Grading Practices," Journal of Economic Education 15, 1984: 197-203.

Dyck, Alexander; and Zingales, Luigi. "The Corporate Governance Role of the Media," Working paper, University of Chicago, 2002.

The Economist. "All Shall Have Prizes," April 12, 2001.

Gibbons, Robert; and Waldman, Michael. "A Theory of Wage and Promotion Dynamics Inside Firms," Quarterly Journal of Economics 114, November 1999: 1321-1358.

Juola, Arvo E. "Illustrative Problems in College-Level Grading," Personnel and Guidance Journal, September 1968: 29-33.

Kelley, Allen C. "Uses and Abuses of Course Evaluations as Measures of Educational Output," Journal of Economic Education 4, Fall 1972: 13-18.

Kolevzon, M.S. "Grade Inflation in Higher Education: A Comparative Study," Research in Higher Education 15, 1981: 195-212.

Kremer, Michael. "The O-Ring Theory of Economic Development," Quarterly Journal of Economics 108, August 1993: 551-575. 
Kuh, G.; and $\mathrm{Hu}, \mathrm{S}$. "Unraveling the Complexity of the Increase in College Grades from the Mid-1980s to the Mid-1990s," Educational Evaluation and Policy Analysis 20, Fall 1999: 297-320.

Kydland, Finn; and Prescott, Edward. "Rules Rather Than Discretion: The Inconsistency of Optimal Plans," Journal of Political Economy 85, June 1977: 471-491.

Lambert, Craig. "Desperately Seeking Summa," Harvard Magazine, May-June 1993: 3640.

Levine, A; and Cureton, J.S. "Collegiate Life: An Obituary," Change 30(3), 1998: 1217,51 .

McKenzie, Richard B. The Political Economy of the Education Process. Boston: Martinus Nijhoff, 1979.

Milgrom, Paul; and Roberts, John. "Comparing Equilibria," American Economic Review 84, June 1994: 441-459.

Millman, J.; Slovaced, S.P.; Kulick, E.; and Mitchell, K.J. "Does Grade Inflation Affect the Reliability of Grades?" Research in Higher Education 19, 1983: 423-429.

Morgan, John; and Stocken, Phillip C. "An Analysis of Stock Recommendations." RAND Journal of Economics 34, Spring 2003: 183-203.

Mullaninathan, Sendhil; and Shleifer, Andrei. "Media Bias," Working paper, Harvard University, 2002.

Nelson, Jon P.; and Kathleen A. Lynch. "Grade Inflation, Real Income, Simultaneity, and Teaching Evaluations," Journal of Economic Education 15, Winter 1984: 21-37.

The New York Times. "Yale Moves to Make Cum Laude Mean More," May 22, 1988.

Nichols, Alan; and John C. Soper. "Economic Man in the Classroom," Journal of Political Economy 80, September 1972: 1069-1073.

Ostrovsky, Michael; and Schwarz, Michael. "Equilibrium Information Disclosure: Grade Inflation and Unraveling," Working paper, Harvard University, 2003.

Perrin, Noel. "How Students at Dartmouth Came to Deserve Better Grades," Chronicle of Higher Education, October 9, 1998.

Rogoff, Kenneth. "Reputational Constraints on Monetary Policy," Carnegie-Rochester Conference Series on Public Policy 26, 1987: 141-181.

Sabot, R.; and Wakeman-Linn, J. "Grade Inflation and Course Choice," Journal of Economic Perspectives 5, Winter 1991: 159-170.

Spence, Michael. "Job Market Signaling," Quarterly Journal of Economics87, 1973: 355374 .

Wilson, B.P. "The Phenomenon of Grade Inflation in Higher Education," National Forum, Fall 1999: 38-41.

Zangenehzadeh, Hamid. "Grade Inflation: A Way Out," Journal of Economic Education 20, Summer 1988: 217-223. 